\title{
Promotion of growth and apoptosis in c-myc nullizygous fibroblasts by other members of the myc oncoprotein family
}

\author{
M Landay ${ }^{1}$, SK Oster, ${ }^{2,3}$ F Khosravi ${ }^{2,3}$, LE Grove ${ }^{1}$, X Yin ${ }^{1}$, \\ $J_{\text {Sedivy }}{ }^{4}$, LZ Penn ${ }^{2,3}$ and EV Prochownik ${ }^{\star, 1,5,6}$ \\ 1 Section of Hematology/Oncology, Department of Pediatrics, Children's \\ Hospital of Pittsburgh, Pittsburgh, USA \\ 2 Department of Medical Biophysics, Children's Hospital of Pittsburgh, \\ Pittsburgh, USA \\ ${ }^{3}$ Ontario Cancer Institute, University Health Network, The University of Toronto, \\ Toronto, Canada \\ ${ }^{4}$ Division of Biology and Medicine, Brown University, Toronto, Canada \\ ${ }^{5}$ Department of Molecular Genetics and Biochemistry, The University of \\ Pittsburgh Medical Center, Pittsburgh, USA \\ ${ }^{6}$ The University of Pittsburgh Cancer Institute, Pittsburgh, USA \\ * Corresponding author: EV Prochownik, MD, PhD, Section of Hematology/ \\ Oncology, Children's Hospital of Pittsburgh, 3705 Fifth Avenue, Pittsburgh, \\ PA 15213, USA. Tel: (412) 692-6797; Fax: (412) 692-5723; \\ E-mail: edward_prochownik@poplar.chp.edu
}

Received 6.1.00; revised 16.3.00; accepted 28.3.00

Edited by CJ Thiele

\begin{abstract}
c-myc nullizygous fibroblasts (KO cells) were used to compare the abilities of c-myc, N-myc and L-myc oncoproteins to accelerate growth, promote apoptosis, revert morphology, and regulate the expression of previously described c-myc target genes. All three myc oncoproteins were expressed following retroviral transduction of $\mathrm{KO}$ cells. The proteins all enhanced the growth rate of KO cells and significantly shortened the cell cycle transition time. They also accelerated apoptosis following serum deprivation, reverted the abnormal KO cell morphology, and modulated the expression of previously described c-myc target genes. In most cases, Lmyc was equivalent to $\mathrm{c}-\mathrm{myc}$ and $\mathrm{N}$-myc in restoring all of the c-myc-dependent activities. These findings contrast with the previously reported weak transforming and transactivating properties of L-myc. Myc oncoproteins may thus impart both highly similar as well as dissimilar signals to the cells in which they are expressed. Cell Death and Differentiation (2000) 7,697705.
\end{abstract}

Keywords: myc; max; apoptosis; green fluorescent protein; cell cycle; oncogene

Abbreviations: GFP, green fluorescent protein; KO cells, (c-myc) knockout cells; PBS, phosphate-buffered saline

\section{Introduction}

The c-myc oncoprotein plays important roles in proliferation, differentiation, apoptosis, and transformation. ${ }^{1,2} \mathrm{c}$-myc is expressed in proliferating cells where it is induced with immediately-early kinetics in response to mitogenic stimulation. ${ }^{3-6}$ In contrast, the withdrawal of growth factors is associated with a rapid decline in c-myc. Inhibition of c-myc retards S-phase progression, whereas its conditional expression in quiescent cells can promote abortive S-phase entry in the absence of growth factors. ${ }^{7-10}$

$\mathrm{N}$-myc and L-myc are c-myc-related genes ${ }^{11-13}$ whose spatial and temporal expression in the developing embryo are distinct from one another as well as from c-myc. ${ }^{14-16}$ This has suggested that the three myc proteins serve different functions, a notion underscored by the finding that L-myc is only $1-10 \%$ as efficient as c-myc or $\mathrm{N}$-myc in transforming primary fibroblasts and that it contains a comparatively weak transactivation domain. ${ }^{17,18}$ Other evidence for functional differences among the three myc proteins stems from the different phenotypes of c-myc, Nmyc, and L-myc knockout mice, ${ }^{16,19,20}$ the association of each myc gene with a distinctive spectrum of naturally occurring neoplasms ${ }^{21}$ and their differential abilities to alter the sensitivity of cells to chemotherapeutic drugs. ${ }^{22}$ In contrast, each myc protein is equally effective at enhancing the apoptotic response of hematopoietic cells to growth factor withdrawal. ${ }^{22}$ Furthermore, under certain conditions, L-myc can promote the growth of transformed cells as well as, or better than, c-myc. ${ }^{17}$ Together, these observations suggest that, while some functions of myc proteins are overlapping and redundant, others are unique.

One problem in attempting to analyze differences among the myc oncoproteins is the virtually ubiquitous expression of c-myc which might confound the phenotype resulting from N-myc and L-myc over-expression. Recently, a Rat1 fibroblast cell line (HO15.19) has been described in which c-myc was inactivated by homologous recombination. ${ }^{23}$ In addition to the complete absence of functional c-myc mRNA and protein, these 'knockout' cells (hereafter referred to as KO cells) grow much more slowly than the parental cells from which they were derived, have prolonged $\mathrm{G}_{1}$ and $\mathrm{G} 2 / \mathrm{M}$-phases, and express neither $\mathrm{N}$ myc nor L-myc mRNA or protein. KO cells thus represent a unique model system in which to study the properties of individual myc proteins without concern for the contribution made by endogenous c-myc.

In the current study, we have expressed individual members of the myc oncoprotein family in KO cells. We show that all three myc members could rescue the growth and cell cycle defects of these cells, promote apoptosis following serum withdrawal, and restore parental cell morphology. Somewhat surprisingly, L-myc was either as effective or only marginally less effective than c-myc or $\mathrm{N}$ myc in restoring these properties. N-myc and, to a lesser extent, L-myc were also able to regulate previously described c-myc target genes in these cells, including $\mathrm{cad},{ }^{24}$ gadd $45,{ }^{25}$ and c-myc itself. ${ }^{26}$ Our findings argue that, to a large extent, the three myc proteins are functionally quite similar. 
However, subtle differences do exist, indicating that they may not be strictly interchangeable.

\section{Results}

\section{Expression of c-, N-, and L-myc in KO fibroblasts after retroviral transduction}

$\mathrm{KO}$ fibroblasts ${ }^{23}$ were infected with retroviruses encoding cmyc, N-myc, or L-myc (see Materials and Methods). Each vector also encoded GFP, expressed bicistronically from the same transcript as that encoding the respective myc oncoprotein. ${ }^{27,28} \mathrm{~A}$ control infection was performed with the parental retroviral vector. Following infection, GFP-positive cells, representing a minimum of several hundred independent infection events, were isolated aseptically by FACS, pooled, and expanded for further analyses. We refer to these cell lines as c-myc, N-myc, L-myc, or GFP (control) cells. Uninfected Rat1 parental fibroblasts, designated TGR-1, and $\mathrm{KO}$ cells, served as additional control cell lines.

As a first step in characterizing the above cell populations, we performed a series of Northern and Western blots to confirm the expression of GFP and/or myc mRNA and protein. As seen in Figure 1A, the expected genome length GFP-encoding transcripts were detected in all cell populations which had been infected with recombinant retroviruses. As anticipated, GFP transcripts were not detected in either uninfected $\mathrm{KO}$ or TGR-1 cells. Transcripts in GFP cells were also noted to be of two sizes, suggesting the occurrence of alternate splicing. Of further note was that the GFP transcripts in cmyc, N-myc, and L-myc cells were less abundant than in GFP cells, indicating either that the presence of myc sequences reduced the inherent rates of retroviral transcription, or that higher levels of myc protein expression were detrimental to survival (see Discussion). This was consistent with our observation that GFP cells were considerably brighter than their myc-transduced counterparts when examined by UV microscopy (not shown).

Additional Northern blot analyses with specific myc probes demonstrated the presence of high levels of each myc transcript in the corresponding cell line. In all cases, these transcripts were of the same size as those previously detected with the GFP probe, a finding consistent with the idea that myc and GFP were encoded by a common mRNA. Endogenous c-myc message of the expected size was also detected in the parental TGR-1 cell line and was appropriately down-regulated in response to serum
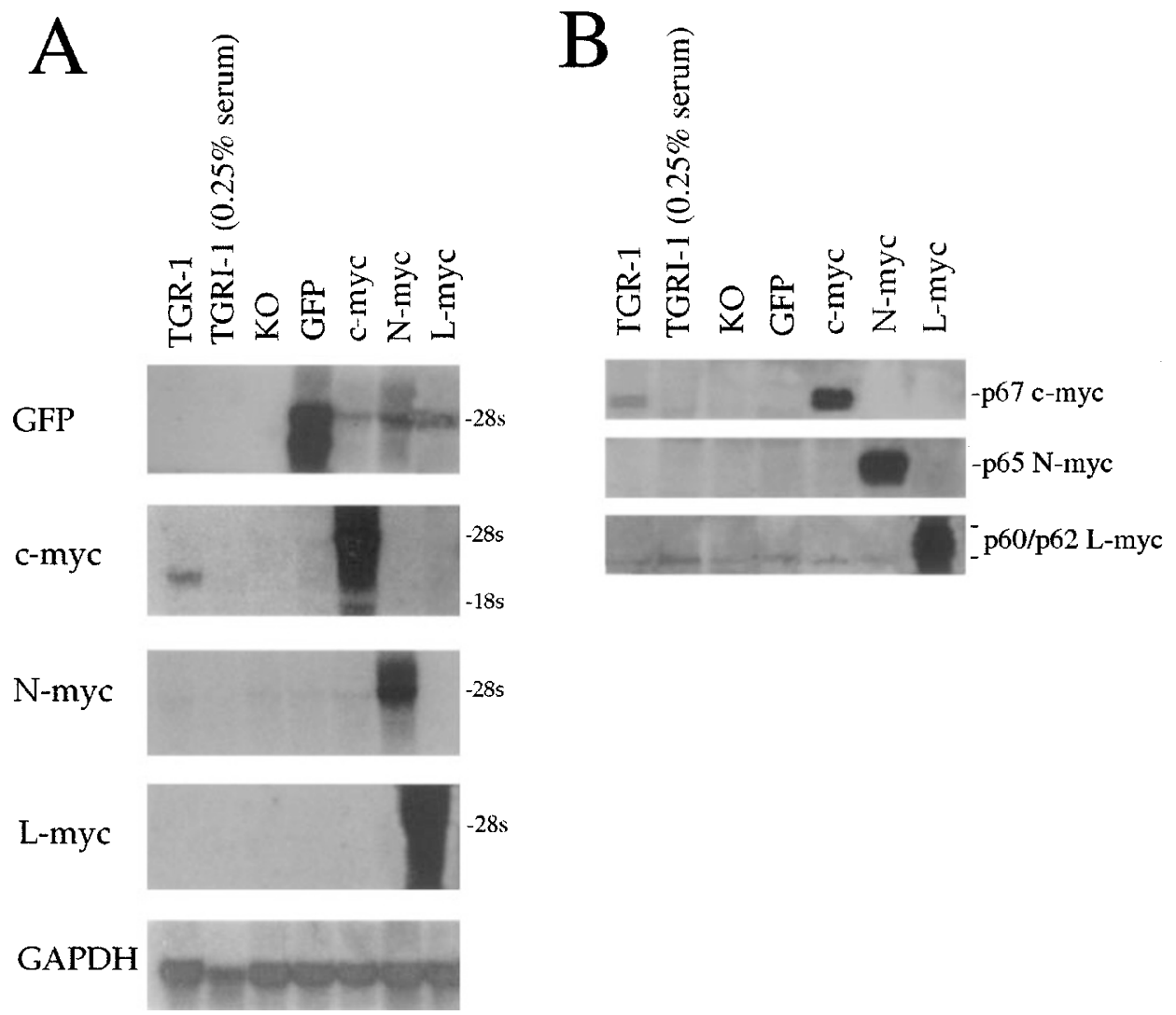

Figure 1 Expression of myc transcripts and proteins. The indicated cultures were harvested during log-phase growth in $10 \%$ serum. TGR-1-(0.25\% serum) refers to parental TGR-1 cells which were serum starved $(0.25 \%)$ for $48 \mathrm{~h}$ in order to reduce endogenous c-myc mRNA and protein. (A) Northern blots of total RNAs $(10 \mu \mathrm{g} /$ lane) from the indicated cell lines were hybridized with the cDNA probes indicated to the left of each panel. These included GFP, C-, N-, or L-myc, and GAPDH as a control for RNA loading. (B) Western blots containing $25 \mu \mathrm{g} / \mathrm{lane}$ of total protein from each of the indicated cell lines were incubated with c-myc, N-myc, or L-mycspecific antibodies and developed using a chemiluminescent procedure 
deprivation. As previously reported, neither c-myc, N-myc, nor L-myc transcripts were detected in KO cells. ${ }^{23}$

Western blotting was next used to identify expression of c-myc, N-myc, and L-myc proteins in the various cell lines. As seen in Figure 1B, expression of c-myc was detected in c-myc cells but not in KO, N-myc or L-myc cells. Parental TGR-1 cells also expressed low levels of endogenous cmyc protein whose disappearance following prolonged serum deprivation mirrored that of endogenous c-myc transcripts (Figure 1A). Similar experiments revealed the expression of $\mathrm{N}$-myc and L-myc proteins in their respective cell lines. Consistent with the Northern blotting results described above, neither N-myc nor L-myc proteins were detected in TGR-1, KO or GFP cells. From these experiments, we conclude that successful expression of c-myc, N-myc, and L-myc in KO cells was accomplished by retroviral transduction.

\section{c-, N-, and L-myc overexpression increases the growth rate of KO cells}

It has been previously reported that $\mathrm{KO}$ cells grow much more slowly than parental TGR-1 cells and that ectopic c-myc expression reverses this deficit. ${ }^{23,29}$ To determine whether $\mathrm{N}$ myc and L-myc could substitute for c-myc, we compared the growth rates of each of the six cell lines described above. As seen in Figure 2, both KO and GFP cells grew much more slowly than parental TGR-1 cells, with doubling times of $52-$ $54 \mathrm{~h}$ as has been previously reported. ${ }^{23,29} \mathrm{c}$-myc and N-myc cells grew significantly faster than TGR-1 cells and were indistinguishable from one another. In several independent experiments, L-myc cells displayed an intermediate behavior, growing more rapidly than TGR-1 cells but more slowly than either c-myc or N-myc cells.

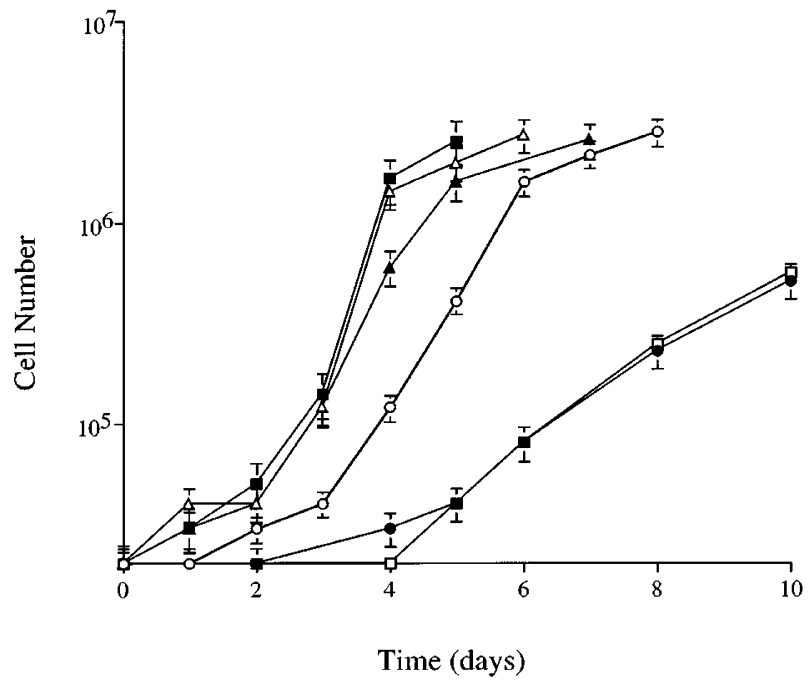

Figure 2 Growth curves of fibroblast cultures. $35 \mathrm{~mm}$, six well plates were seeded with $2 \times 10^{4}$ cells/well of each cell type on day 0 . Cells counts were then performed every 1-2 days. Shown here are the averages of three independent experiments $\pm 1 \mathrm{~S}$.E. Cells included TGR-1 (O); KO (๑); GFP $(\square)$; c-myc $(\boldsymbol{\square})$; N-myc $(\triangle)$; and L-myc $(\boldsymbol{\Delta})$. Calculated doubling times were $25.8( \pm 3.3) \mathrm{h}$ for TGR-1; $54.1( \pm 3.2) \mathrm{h}$ for KO; $52.2( \pm 3.3) \mathrm{h}$ for GFP; 18.2 $( \pm 2.5) \mathrm{h}$ for c-myc; $19.9( \pm 1.9) \mathrm{h}$ for N-myc; and $21.6( \pm 1.8) \mathrm{h}$ for L-myc
Among the deficits of $\mathrm{KO}$ cells is the prolongation of both G1 and G2/M-phases compared to TGR-1 cells. ${ }^{23} \mathrm{We}$ therefore next studied how the expression of each of the myc proteins influenced the ability of serum-deprived cells to re-enter the cell cycle following serum stimulation. Each of the six cell populations was maintained in $0.25 \%$ serum, and at $>95 \%$ viability, for 4 days at which time they were stimulated to proliferate by the addition of fresh medium containing $20 \%$ serum. At various times thereafter, the percentage of cells in each phase of the cell cycle was determined by fluorescence-activated cell sorting (FACS). As seen in Figures 3 and 4, all six cell populations had similar cell cycle profiles under conditions of logarithmic growth. Following serum deprivation, TGR-1 cells efficiently arrested in G0/G1. Each of the other cell lines showed a somewhat less efficient G0/G1 arrest that was mostly attributable to a higher fraction of cells remaining in $\mathrm{G} 2 / \mathrm{M}$ following serum removal. Culturing these cells for up to a week in $0.25 \%$ serum did not significantly enhance the degree of G0/G1 accumulation (not shown). Following stimulation with $20 \%$ serum, quiescent TGR-1 cells efficiently and synchronously entered S-phase. By $16 \mathrm{~h}$, the vast majority of these cells $(77 \%)$ were in S-phase, although no change in the fraction of cells in G2/M had yet occurred. By $20 \mathrm{~h}$, the percentage of cells in S-phase had declined due to their coordinated entry into G2/M. KO cells and GFP cells entered the cell cycle much more slowly. For example, by $16 \mathrm{~h}$, the fraction of cells in S-phase had increased only from 17 to $25 \%$ for KO cells and from $19-$ $26 \%$ for GFP cells. After $24 \mathrm{~h}$ of serum stimulation, nearly half of these cells still remained in G0/G1 and no change in the G2/M populations had occurred. In contrast, c-myc, $\mathrm{N}$ myc, and L-myc cells entered S-phase and G2/M significantly more rapidly than TGR-1 cells. For example, by $16 \mathrm{~h}$, all three myc cell lines already showed $50-100 \%$ increases in their G2/M populations. Although L-myc cells appeared to move through S-phase and into $\mathrm{G} 2 / \mathrm{M}$ as rapidly as c-myc and $\mathrm{N}$-myc cells, they did exit G0/G1 somewhat more slowly as evidenced by the nearly twofold greater fraction of L-myc cells in G0/G1 at $16 \mathrm{~h}$ compared to c-myc and N-myc cells. This was consistent with the slower growth rate of L-myc cells in comparison to their cmyc and N-myc counterparts.

From the above experiments, we conclude that the enhanced growth rates of c-myc, N-myc, and L-myc cells, relative to that of all other cells, correlates with a decrease in the lengths of their cell cycle. These findings are consistent with the previous report of Matayek et al. ${ }^{23}$ The accelerated rate of transit through all phases of the cell cycle for c-myc, N-myc, and L-myc cells explains the highly similar profiles of the logarithmically growing populations in the face of vastly different growth rates (Figure 4).

\section{c-, N-, and L-myc overexpression increase the rate of apoptosis and restore normal morphology}

The dysregulation of c-myc in fibroblasts and several other cell types results in an accelerated rate of apoptotic death following the withdrawal of serum or other obligate 
TGR-1 Ohr

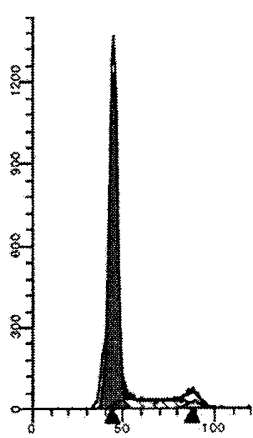

GFP Ohr

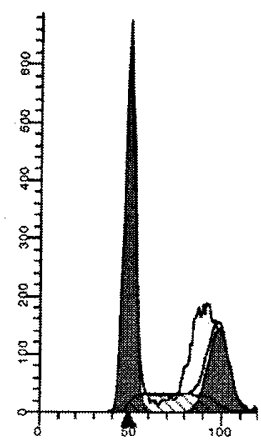

N-myc Ohr

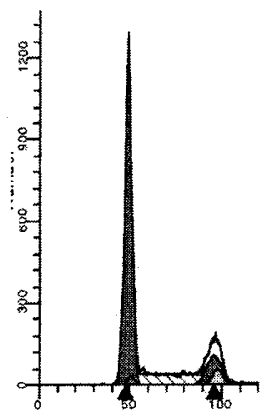

TGR-1 16hr

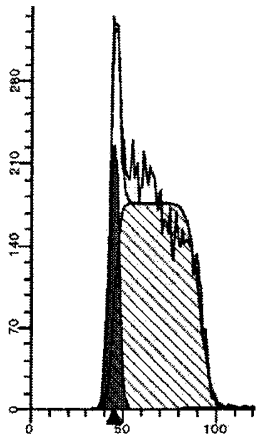

GFP $16 \mathrm{hr}$

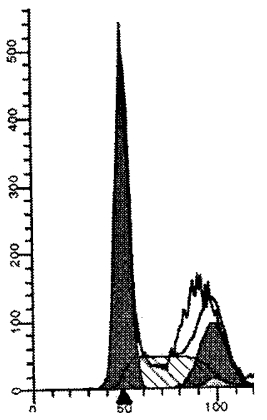

N-myc $16 \mathrm{hr}$

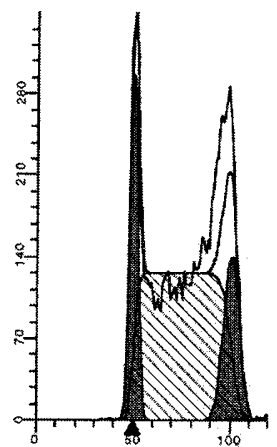

myc KO Ohr

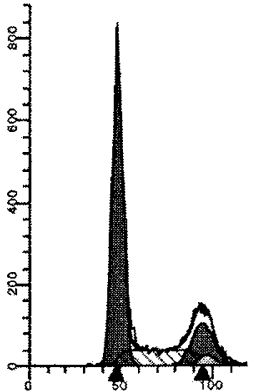

c-myc $\mathrm{Ohr}$

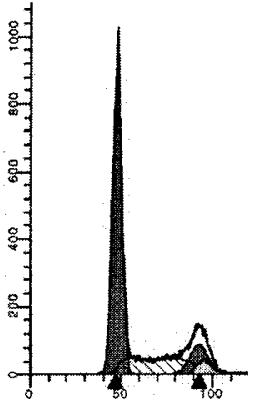

L-myc Ohr

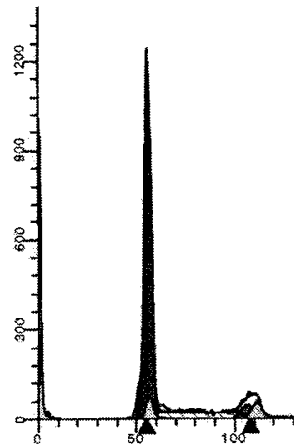

myc KO 16hr

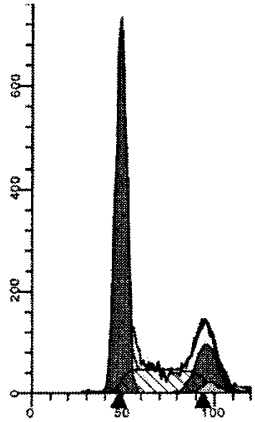

c-myc $16 h r$

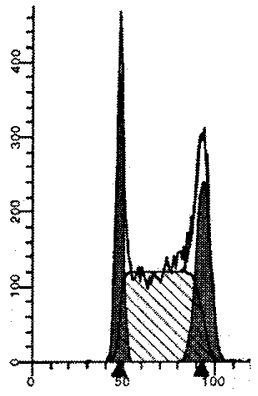

L-myc $16 \mathrm{hr}$

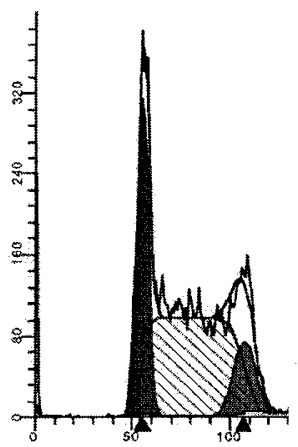

Figure 3 Cell cycle profiles. Log-phase or serum-deprived cells, or serum-deprived cells stimulated for the indicated periods of time with serum were prepared as described in the legend to Table 1 . At least $10^{4}$ propidium iodide-stained nuclei were evaluated by FACS as described in the legend to Table 1

cytokines. ${ }^{30-32}$ We thus compared the rates of cell death in the above six cell lines following the removal of serum. In the first such experiment, each cell line was maintained in logarithmic growth until achieving $60-80 \%$ confluency. The cells were then washed twice with PBS and maintained in serum-free medium for the duration of the experiment. The number of viable cells was then determined at regular intervals. As seen in Figure 5, TGR-1, KO, and GFP cells were relatively resistant to serum deprivation, and generally remained $>80 \%$ viable throughout the duration of the experiment. At later times, a somewhat greater degree of cell death was noted in TGR-1 cells, consistent with previous observations that endogenous levels of c-myc may regulate apoptosis. ${ }^{33}$ In marked contrast to these relatively slow rates of cell death, c-myc and $\mathrm{N}$-myc cells rapidly lost viability at roughly equivalent rates. Although L-myc cells also showed a 


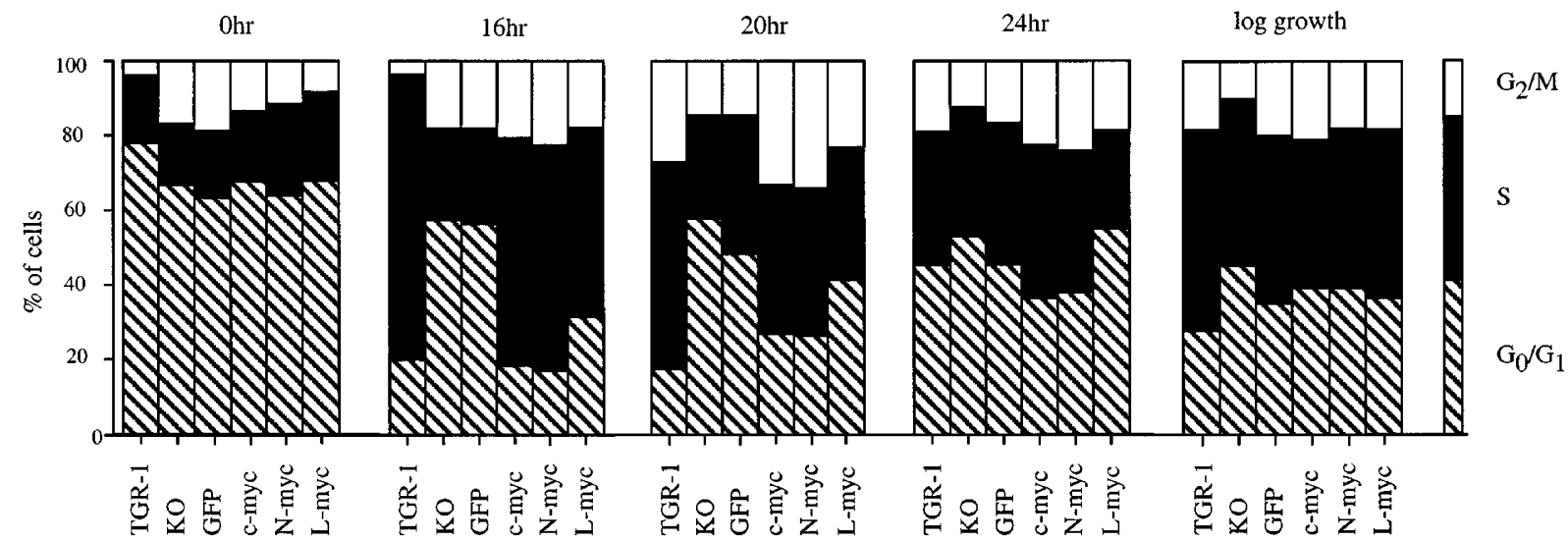

Figure 4 Cell cycle analysis of fibroblast cell lines. Cells were maintained in $100 \mathrm{~mm}$ tissue culture plates until reaching $50-75 \%$ confluence. At this time, one plate from each group was used to determine the cell cycle profile of the logarithmically growing population (rightmost panel). The remaining plates were washed three times with PBS and recultured in medium containing $0.25 \%$ serum for 4 days. One plate from this group was again used to determine the cell cycle profile of the serum-deprived population $(0 \mathrm{~h})$. The remaining plates were then stimulated with fresh medium containing $20 \%$ serum. Cell cycle profiles were dete rmined 16 , 20 , and $24 \mathrm{~h}$ later. The fraction of each population in G0/G1, S, and G2/M-phases was determined using ModFit LT software (Becton-Dickinson). Numbers shown represent the average of $3-5$ independent experiments. Standard errors were generally $<10 \%$ among different experiments

greatly enhanced rate of apoptosis, it was slightly slower than that of their c-myc and N-myc counterparts.

In other experiments, the apoptotic nature of the cell death observed in Figure 5 was documented by phasecontrast microscopy and by TUNEL assay. As seen in Figure 6 (top two rows of panels), serum deprivation of either TGR-1, KO, or GFP cells for up to 7 days resulted in no discernible change in their phase-contrast appearance and only modest increases in the number of TUNELpositive cells compared to non-serum-deprived controls (middle two rows of panels). By contrast, all three myc oncoprotein-expressing cell lines showed large increases in apoptotic populations. Significant increases in the number of apoptotic cells were noted as early as 1-2 days following the removal of serum, with marked apoptotic death being observed on days 3-5 (as shown here). By 7 days, a time at which TGR-1, KO, and GFP cells still demonstrated little evidence of apoptosis, most of the myc cells had detached from their plates.

Another feature of $\mathrm{KO}$ cells affected by the overexpression of all three myc oncoproteins was their morphologic appearance during logarithmic growth (Figure 6 , bottom two rows of panels). Under these conditions, TGR-1 cells maintained a typical, elongated, fibroblastoid appearance. The cells also tended to organize themselves into groups sharing a common axis. Large open areas between such groups, which were eventually filled in as confluency was achieved, were also noted. Individual $\mathrm{KO}$ and GFP cells, on the other hand, were more cuboidal in appearance, had a thinner appearing cytoplasm, and grew in a disorganized fashion, with no evidence for the large open areas seen in the TGR-1 cultures. The expression of all three myc oncoproteins restored 'normal', TGR-1-like morphology and organization to KO cells.

From the above studies, we conclude that all three myc oncoproteins were able to accelerate apoptosis in $\mathrm{KO}$ cells following the withdrawal of serum. All three oncoproteins also allowed $\mathrm{KO}$ cells to resume a normal appearing

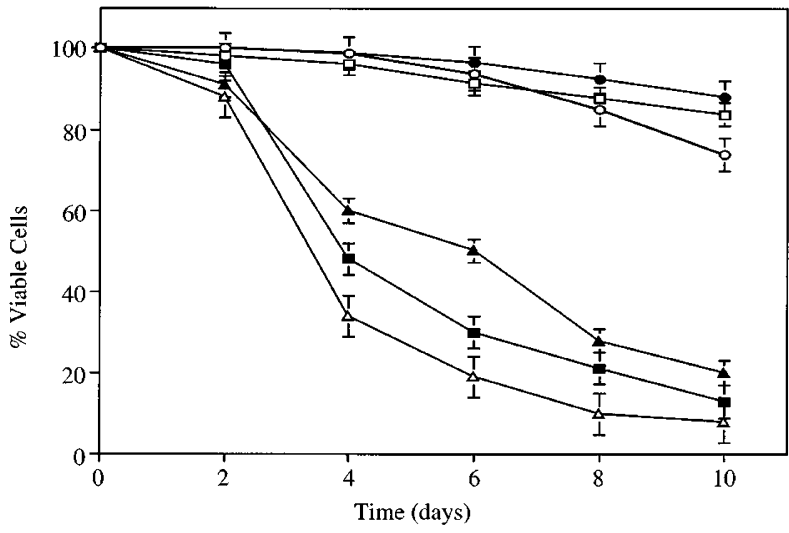

Figure 5 Viability of fibroblast cell lines after serum deprivation. Each cell line was seeded into 6 well plates at a density of $10^{5}$ cell/well and allowed to achieve approximately $80 \%$ confluence. Cells were then washed three times in PBS and cultured in complete medium lacking serum. Viable cells were enumerated at the indicated times using Trypan Blue exclusion. The identity of each cell line is as designated in the legend to Figure 2. The results shown represent the average of $3-5$ independent experiments \pm 1 S.E.

morphology and organizational pattern highly reminiscent of the TGR-1 parental cell line.

\section{Restoration of c-myc target gene regulation}

Although a number of putative c-myc-regulated target genes have been identified, ${ }^{34}$ only three have been shown to be deregulated in $\mathrm{KO}$ cells. ${ }^{29}$ These include cad, which encodes a trifunctional enzyme catalyzing the first three steps in the de novo synthesis of pyrimidines, ${ }^{24}$ gadd45, a gene induced by growth arrest and DNA damage, ${ }^{25}$ and c-myc itself. ${ }^{26}$ Although $\mathrm{KO}$ cells lack expression of functional c-myc protein, (Figure 1$)^{23}$ the endogenous c-myc promoter is still down-regulated in myc cells, as determined by assessment of the level of neo gene expression. ${ }^{29}$ As a consequence of its 
having been embedded within the second exon of c-myc during the construction of the $\mathrm{KO}$ cell line, neo serves as a marker for c-myc promoter-initiated transcription and autosuppression. ${ }^{29}$ To measure steady-state levels of the above c-myc-regulated transcripts, Northern blots were performed with total mRNAs from each of the above six cell lines. Blots
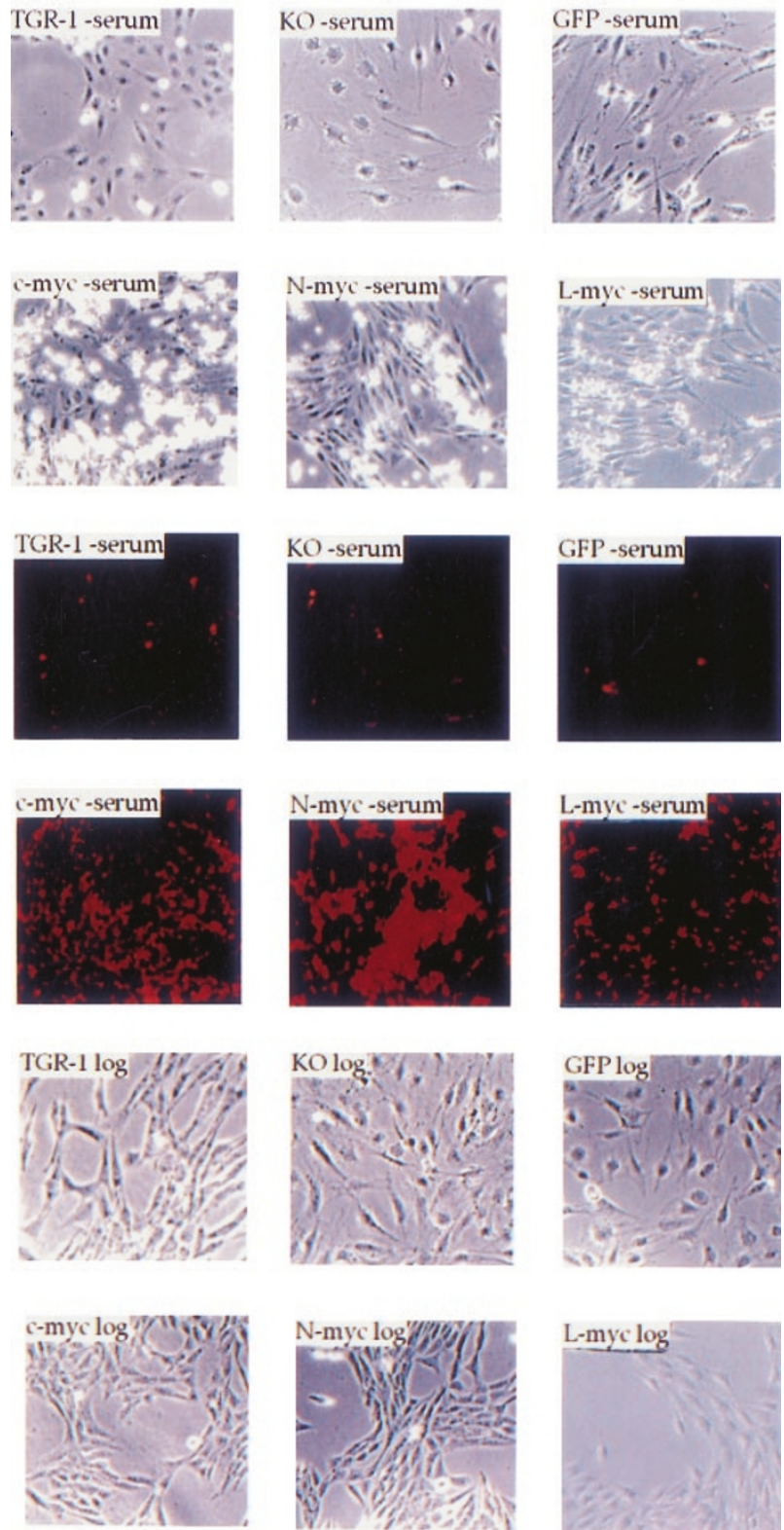

Figure 6 Morphology and apoptosis of fibroblast cell lines. The top two rows of panels show phase-contrast photos of cell lines following 7 days of serum deprivation in the case of TGR-1, KO, and GFP cells, and 4 days serum deprivation in the case of c-myc, N-myc, and L-myc cell lines. Apoptotic cells are indicated by their typical rounded, refractile appearance. The middle two rows of panels shows the results of TUNEL assays performed on each of the cell lines deprived of serum for the times stated above. The bottom two rows of panels show phase-contrast micrographs of the indicated logarithmically growing populations of cells. Of note is the organized and drawn-out, fibroblastoid appearance of TGR-1, c-myc, N-myc, and L-myc cells. In contrast, KO and GFP cells were less drawn, possessed a thinner cytoplasm, and grew in a disorganized manner ( $\times 100$ in all cases) were then hybridized with ${ }^{32} \mathrm{P}$-labeled cDNA probes for cad, gadd45, or neo (to detect endogenous c-myc; see above). As seen in Figure 7, cad gene expression was approximately threefold higher in TGR-1 cells than in either KO or GFP cells, thus confirming the partial c-myc-dependent nature of its expression. Elevated expression of cad was seen in all three cell lines expressing myc oncoproteins. Although a somewhat higher level of expression was consistently seen in c-myc cells than in N-myc or L-myc, this difference was generally $<$ twofold.

In contrast to the up-regulation of cad by myc oncoproteins, gadd45 and c-myc (as determined by neo transcript levels) were down regulated. In the former case, c-myc, N-myc, and L-myc appeared to be equally effective at suppressing the expression of gadd45 (<twofold differences), whereas in the latter case, L-myc was considerably less effective than either c-myc or N-myc in down-regulating the endogenous c-myc promoter.

From the foregoing experiments, we conclude that the regulation of at least some c-myc target genes can be assumed by both N-myc and L-myc. L-myc however appears less effective than the other myc oncoproteins in its ability to down-regulate the c-myc promoter.

\section{Discussion}

Although c-myc, N-myc, and L-myc have been implicated in the causation of a large number of different human neoplasms, dysregulation of each tends to be associated with specific tumor subtypes. ${ }^{21}$ Homozygous targeted inactivation of these genes in mice results in widely different phenotypes, ranging from embryonic lethality in the case of cmyc and $\mathrm{N}$-myc to no discernible consequences in the case of L-myc. ${ }^{16,19,20}$ Recent direct comparisons of the effects of cmyc, N-myc, and L-myc overexpression in hematopoietic cells have shown that all three oncoproteins are equally effective at promoting apoptosis in response to cytokine withdrawal but differentially affect apoptosis in response to DNA damaging cytotoxic drugs. ${ }^{22}$ Together with previously noted differences in tissue-specific expression ${ }^{14-16}$ these studies indicate, albeit indirectly, that, while the three myc oncoproteins can substitute functionally for one another under many circumstances, they are not strictly interchangeable.

A potential problem in comparing myc oncoproteins is the contribution made by endogenous $c-m y c$, a gene that is ubiquitously expressed in rapidly proliferating tissues. ${ }^{2}$ In order to circumvent this problem, we have made use of a recently described $\mathrm{c}-m y c$ nullizygous fibroblast cell line (KO cells). ${ }^{23}$ Because $\mathrm{KO}$ cells neither express endogenous $\mathrm{C}-$ myc protein nor show compensatory increases in N-myc or L-myc expression, they serve as a useful model system in which to compare and contrast the individual members of the myc family.

Using retroviral transduction, we expressed c-myc, Nmyc, and L-myc in KO cells (Figure 1). In all three cases, the myc proteins stimulated the growth of $\mathrm{KO}$ cells beyond that of the parental TGR-1 cell line. This most likely reflects the higher levels of myc proteins relative to that of endogenous c-myc expressed in TGR-1 cells and is consistent with the known ability of c-myc to stimulate 


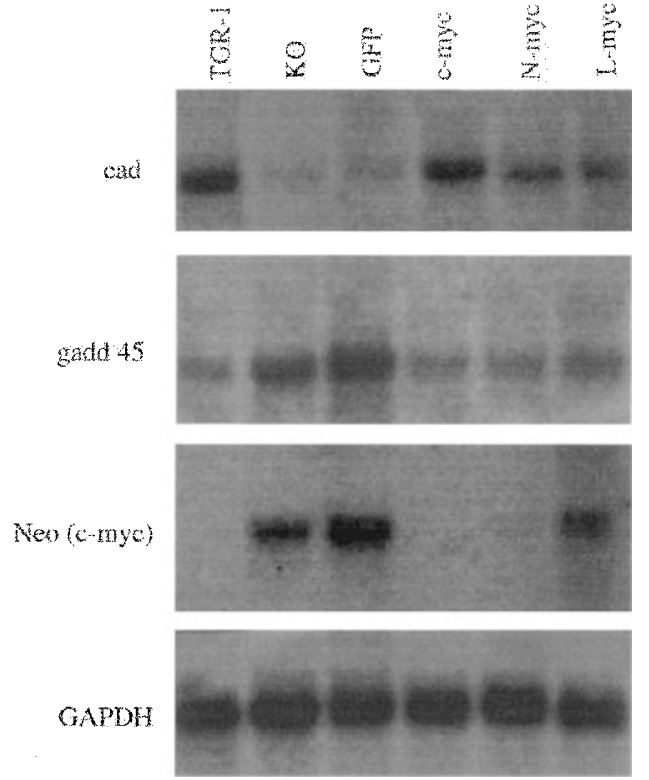

Figure 7 Expression of c-myc-regulated genes in fibroblast cell line. Northern blots containing $10 \mu \mathrm{g}$ of total RNA from each of the indicated cell lines were hybridized with DNA probes for the genes indicated to the left of the respective panel. These included cad, gadd45, neo, and GAPDH as a control for RNA loading and transfer

proliferation in other systems. ${ }^{35,36}$ These experiments establish that the abilities of N-myc and L-myc to stimulate growth do not require any additional contribution from endogenous c-myc.

One notable observation was the lower abundance of retroviral transcripts in c-myc, N-myc, and L-myc cells compared to GFP cells (Figure 1A). The two most likely possibilities to explain this are that retroviral vectors containing myc transcripts are less efficiently transcribed, or that high level expression of myc proteins is detrimental to the survival of the cell. This latter possibility is certainly consistent with the observation that all three myc cell lines were predisposed to apoptosis (Figures 4 and 5). It is also consistent with our observation of much higher levels of retroviral transcripts in $\mathrm{KO}$ cells transduced with an L-myc retroviral vector harboring a frame-shift mutation in the Lmyc cDNA. These cell show a KO-like morphology, grow as slowly as KO and GFP cells, and are relatively resistant to apoptosis following serum deprivation (not shown). Thus, the inability of myc-expressing $\mathrm{KO}$ cells to sustain levels of retroviral transcripts as high as those achieved in GFP cells is quite likely due to the tendency of the former to undergo apoptosis once a certain threshold of oncoprotein expression is exceeded.

It has been previously demonstrated that c-myc and $\mathrm{N}$ myc are equivalent in their abilities to transform primary embryonic fibroblasts in vitro in association with activated ras oncogenes, whereas L-myc is only $1-10 \%$ as efficient. ${ }^{17,37,38}$ Although this difference was initially attributed to the weaker transactivation domain of Lmyc, ${ }^{18}$ it has recently been shown that transformation and transactivation can be genetically separated. ${ }^{39,40}$ Indeed, the former function has been shown to map to Myc Box II, a highly conserved, approximately 20 amino acid segments located in the C-terminus of the transactivation domain. ${ }^{40,41}$ That L-myc is as effective as c-myc and N-myc in restoring TGR-1-like morphology and nearly as efficient at restoring growth and promoting apoptosis in response to serum deprivation indicates that these functions are independent of the ability to transform in cooperation with ras. L-myc also functions nearly as well as c-myc and N-myc in modulating at least some previously described c-mycresponsive genes (Figure 6). ${ }^{29}$ These results are compatible with our own observations that L-myc promotes apoptosis as effectively as c-myc or N-myc in hematopoietic cells deprived of the obligate cytokine interleukin-3. ${ }^{22}$ They are also consistent with previous work showing that primary fibroblasts transformed by L-myc+ras oncogenes grow as rapidly as those transformed by c-myc+ras and have equivalent, or even better, cloning efficiencies in soft agar. ${ }^{17}$ They are further consistent with the recent observations that c-mycS, an internally initiated c-myc protein lacking the first 100 amino acids of the transactivation domain, can accelerate growth and apoptosis and promote anchorage-independent growth of fibroblasts, but is deficient in transactivation. ${ }^{42}$ It is thus tempting to speculate that the poorer transforming ability of L-myc may be related to its failure to down-regulate specific target genes as efficiently as either c-myc or N-myc (Figure 7). A more rigorous testing of this hypothesis will require the identification of additional genes negatively regulated by $\mathrm{c}$ myc. $^{34}$

In summary, the study presented here represents the first direct comparison of the abilities of c-myc, N-myc, and L-myc to influence several aspects of fibroblast biology in the absence of any underlying contribution from endogenous myc proteins. In all situations examined, L-myc was either as effective or only marginally less effective than cmyc or N-myc in restoring to these cells the properties of the parental cell line that expresses endogenous c-myc. Our studies thus suggest that myc oncoproteins are, at least in some respects, functionally much more similar to one another than they are different. Exceptions to this notion include the much weaker transforming ability of Lmyc; the tendency of N-myc and L-myc to impart resistance to cytotoxic drugs, rather than the sensitivity imparted by $\mathrm{c}$ myc; and the lack of a discernible phenotype in the L-myc knockout mouse. ${ }^{16,17,22}$ Defining the factors which determine these similarities and differences are likely to be of considerable importance in understanding the pathways through which myc oncoproteins act to control both normal and neoplastic cellular functions.

\section{Materials and Methods}

\section{Cell lines}

The TGR-1 parental cell line, derived from Rat1 fibroblasts, has been previously described. ${ }^{23} \mathrm{HO} 15.19$ (KO) cells were derived from TGR-1 parental cells and contain a homozygous insertional inactivation of both endogenous c-myc alleles. ${ }^{23}$ Cells were cultured in standard high-glucose-containing Dulbecco's modified Eagle's essential 
medium (D-MEM) containing $10 \%$ calf serum (GIBCO-BRL, Grand Island, NY, USA), $2 \mathrm{mM}$ glutamine, 100 Units $/ \mathrm{ml}$ Penicillin $\mathrm{G}$, and $100 \mu \mathrm{g} / \mathrm{ml}$ Streptomycin. Cultures were maintained continuously in log phase growth and split 1:5 (for TGR-1s) or $1: 3$ (for KOs) upon reaching $80-90 \%$ confluency. Pooled populations of $\mathrm{KO}$ cells, derived by retroviral transduction of myc sequences, were designated c-myc, $\mathrm{N}$-myc, or L-myc, respectively and were maintained like parental TGR1 cells. Control KO cells transduced with the empty retroviral vector were designated GFP (see below).

\section{Retroviral constructions and infections}

cDNAs encoding the full-length c-myc, N-myc, and L-myc proteins, were excised from their parental vectors ${ }^{22}$ and ligated into the multiple cloning site of pBabeMN-IRES-GFP retroviral vector ${ }^{27,28}$ using standard molecular techniques. The resulting retroviral constructs encode a single bicistronic transcript containing the coding sequences of the respective myc and green fluorescent protein (GFP), separated by an internal ribosomal entry site (IRES). To prepare infectious, replication-incompetent viral stocks, retroviral vector DNAs were transfected into the Phoenix-eco packaging cell line (ATCC, Bethesda, MD, USA) using a standard calcium phosphate-based procedure. ${ }^{43}$ Infectious retrovirus was harvested 36-48 $\mathrm{h}$ later and used to infect $\mathrm{KO}$ cells for at least $3 \mathrm{~h}$ in the presence of $10 \mu \mathrm{g} / \mathrm{ml}$ of Polybrene (Sigma, St. Louis, MO, USA). Two to 3 days later, GFP-positive cells were selected aseptically using a fluorescence-activated cell sorter (Becton Dickinson FACStar Plus, San Jose, CA, USA) at a laser setting of $488 \mathrm{~nm}$ using a 530 DF30 filter and CELLQuest acquisition software (Becton-Dickinson). GFP-positive sorted populations were then pooled and expanded for further analysis.

\section{Northern and Western blotting}

For Northern blotting, total RNAs were prepared from semi-confluent cultures seeded in $150 \mathrm{~mm}$ plates as previously described. ${ }^{44}$ Ten $\mu \mathrm{g}$ aliquots of each RNA sample were resolved in 1\% agaroseformaldehyde gels, transferred to Nytran membranes (Schleicher and Schuell, Keane, NH, USA), UV cross-linked, and hybridized under standard conditions ${ }^{45}$ with ${ }^{32} \mathrm{P}-\mathrm{dCTP}$-labeled cDNA probes for the coding regions of GFP, c-myc, N-myc, and L-myc. Specifically, the myc cDNA probes consisted of the same coding region fragments used to construct the retroviral vectors. ${ }^{22}$ Hybridizations with cad, gadd 45 and neo were performed in Ultrahyb solution (Ambion, Austin, TX, USA) using the conditions recommended by the supplier. The blots were then washed and autoradiography performed using Kodak Biomax MS film.

For Western blot analysis, washed and pelleted cells were lysed in $1 \times$ SDS-PAGE loading buffer as previously described. ${ }^{46}$ Twenty-five $\mu \mathrm{g}$ of each lysate was electrophoresed on $10 \%$ SDSpolyacrylamide gels and transferred to PVDF membranes (Millipore, Bedford, CT, USA) using a semi-dry electroblotting apparatus (Owl Scientific, Cambridge, MA, USA). Blots were blocked in PBS-T-5\% non-fat dry milk and probed with rabbit polyclonal antibodies to c-myc, ${ }^{47} \mathrm{~N}$-myc (\#sc-791: Santa Cruz Biotechnology, Inc., Santa Clara, CA, USA), or L-myc (\#sc-790: Santa Cruz), followed by horseradish peroxidase-conjugated goatanti rabbit IgG. After thorough washing in PBS-T, the blots were developed using a chemiluminescent kit (Renaissance, New England Nuclear, Boston, MA, USA) according to the directions of the supplier.

\section{Cell cycle analysis}

Cell cycle profiles on logarithmically growing populations were performed on subconfluent cultures which had been fed with fresh medium 1-2 days prior to harvesting. Serum deprivation of such logarithmically growing cultures was accomplished by washing cells $2-3$ times in serum-free medium or PBS and then culturing in standard medium containing $0.25 \%$ serum for $4-7$ days. Synchronous cell cycle reentry was induced by treating the serum-deprived cells with fresh medium containing $20 \%$ serum. For cell cycle profiles, cells were harvested and prepared as previously described ${ }^{45}$ and analyzed on a FACS Calibur flow cytometer (Becton-Dickinson) using the ModFit LT software package.

\section{TUNEL assays}

Cells grown on glass coverslips were washed three times in PBS and fixed in methanol at $-20^{\circ} \mathrm{C}$ for $30 \mathrm{~min}$. After an additional three washes in PBS, TUNEL assays were performed using the terminal transferase based labeling system (Apoptosis Detection Kit, R\&D Systems, Minneapolis, MN, USA). Incorporated biotin-labeled dUTP was detected with Cy3-labeled Streptavidin (Sigma). Labeled nuclei were viewed under an Olympus BH-2 UV microscope.

\section{Acknowledgments}

We are grateful to Garry Nolan for supplying the pBabeMN-IRES-GFP vector. This work was supported by NIH grants HL33741 and CA78259 to EVP and by a National Cancer Institute of Canada Grant to LZP. SKO was supported by the OGS and MRC of Canada.

\section{References}

1. Evan Gl and Littlewood TD (1993) Curr. Opin. Genet. Dev. 3: 44-49

2. Henriksson M and Luscher B (1996) Adv. Cancer Res. 68: 109-182

3. Kelly K, Cochran BH, Stiles CD and Leder P (1983) Cell 35: 603-610

4. Campisi J, Gray HE, Pardee AB, Dean M and Sonenshein GE (1984) Cell 36: 241-247

5. Hann SR, Thompson CB and Eisenman RN (1985) Nature 314: 366-369

6. Thompson CB, Challoner PB, Neiman PE and Groudine M (1985) Nature 314: 363-366

7. Armelin HA, Armelin CS, Kelly K, Stewart T, Leder P, Cochran BH and Stiles CD (1984) Nature 310: 655-660

8. Heikkila R, Schwab G, Wickstrom E, Loke SL, Pluznik D, Watt R and Neckers LM (1987) Nature 328: $445-449$

9. Prochownik EV, Kukowska-Latallo JF and Rodgers C (1988) Mol. Cell. Biol. 8: 3683-3695

10. Eilers M, Picard D, Yamamoto KR and Bishop JM (1989) Nature 340: 66-68

11. Nau MM, Brooks BJ, Battey J, Sausville E, Gazdor AF, Kirsch IR, McBride OW, Bertness V, Hollis GF and Minna JD (1985) Nature 318: 69-73

12. Kohl NE, Legouy E, DePinho RA, Nissen PD, Smith RK, Gee CE and Alt FW (1986) Nature 319: 73-77

13. Stanton LW, Schwab M and Bishop JM (1986) Proc. Natl. Acad. Sci. USA 83: $1772-1776$

14. Downs KM, Martin GR and Bishop JM (1989) Genes Dev. 3: 860-869

15. Zimmerman K and Alt FW (1990) Oncogene 2: 75-79

16. Hatton KS, Mahon K, Chin L, Chiu FC, Lee HW, Peng D, Morgenbesser SD, Horner J and DePinho RA (1996) Mol. Cell. Biol. 16: 1794-1804

17. Birrer MJ, Segal S, DeGreve JS, Kaye F, Sausville EA and Minna JD (1988) Mol. Cell. Biol. 8: 2668-2673

18. Barrett J, Birrer MJ, Kato GJ, Dosoka-Akita H and Dang CV (1992) Mol. Cell. Biol. 12: $3130-3137$ 
19. Stanton BR, Perkins AS, Tessarolo L, Sassoon DA and Parada LF (1992) Genes Dev. 6: $2235-2247$

20. Davis AC, Wims M, Spotts GD, Hann SR and Bradley A (1993) Genes Dev. 7: $671-682$

21. Nesbit CE, Tersak JM and Prochownik EV (1999) Oncogene 18: 3004-3016

22. Nesbit CE, Grove LE, Yin X and Prochownik EV (1998) Cell Growth Diff. 9: 731 741

23. Matayek MK, Obaya AJ, Adachi S and Sedivy JM (1997) Cell Growth Differ. 8: 1039-1048

24. Milltenberger RJ, Sukow KA and Farnham PJ (1995) Mol. Cell. Biol. 15: 2527 2535

25. Marhin WW, Chen S, Facchini LM, Fornace Jr AJ and Penn LZ(1997) Oncogene 14: $2825-2834$

26. Facchini LM, Chen S, MarlinWW, Lear JN and Penn LZ. (1997) Mol. Cell. Biol. 17: $100-114$

27. Hitoshi Y, Lorens J, Kitada SI, Fisher J, LaBarge M, Ring HZ, Francke U, Reed JC, Kinoshita S and Nolan GP (1998) Immunity 8: 461-471

28. Yasumichi H, Lorens J, Kitada S, Fisher J, LaBarge M, Ring HZ, Francke U, Reed JC, Kinoshita S and Nolan GP (1998) Cell 8: 461-471

29. Bush A, Matayek M, Dugan K, Obaya A, Adachi S, Sedivy J and Cole M (1998) Genes Dev. 12: 3797-3802

30. Askew DS, Ashmun RA, Simmons BC and Cleveland JL (1991) Oncogene 6: 1915-1922

31. Evan GI, Wylie AH, Gilbert CS, Littlewood TD, Land H, Brooks M, Waters CM, Penn LZ and Hancock DC (1992) Cell 69: 119-128

32. Sakamuro D, Eviner V, Elliott KJ, Showe L, White E and Prendergast GC (1995) Oncogene 11: $2411-2418$
33. Shi Y, Glynn JM, Guilbest LJ, Cotter TG, Bissonnette RP and Green DR (1992) Science 257: 212-215

34. Dang CV (1999) Mol. Cell. Biol. 19: 1-11

35. Sorrentino V, Frozdoff V, McKinney MD, Zeitz L and Fleissner E (1986) Proc. Natl. Acad. Sci. USA 83: 8167-8171

36. Stern DF, Roberts AB, Roche NS, Sporn MB and Weinberg RA (1986) Mol. Cell. Biol. 6: 870-877

37. Schwab M, Varmus HE and Bishop JM (1985) Nature 316: 160-162

38. Yancopoulos GD, Nisen PD, Tesfaye A, KohI NE, Goldfarb MP and AltFW (1985) Proc. Natl. Acad. Sci. USA 82: 5455-5459

39. McMahon SB, van BuskirkHA, Dugan KA, Copeland TD and Cole MD (1998) Cell 94: $363-374$

40. Cole MD (1999) Oncogene 18: 16-24

41. Kaye F, Battey J, Nau M, Burke B, Seiffer E, DeGreve J, Birrer M, Sausville E and Minna J (1988) Mol. Cell. Biol. 8: 186-195

42. Xiao Q, Claassen G, Shi J, Adachi S, Sedivy J and Hann SR (1998) Genes \& Dev. 12: $3803-3808$

43. Graham FL and Van der Eb SJ (1973) Virology 52: 456-467

44. Smith MJ, Charron-Prochownik DC and Prochownik EV (1990) Mol. Cell. Biol. 10: $5333-5339$

45. Zhang H, Fan S and Prochownik EV (1997) J. Biol. Chem. 272: 17416-17424

46. Gupta K, Anand G, Yin XY and ProchownikEV (1998) Oncogene 16:1149-1159

47. Sklar MD, Thompson E, Welsh MJ, Liebert M, Harney J, Grossman HB, Smith M and Prochownik EV (1991) Mol. Cell. Biol. 11: 3699-3710 